\title{
Growth and Puberty in Obese Children and Implications of Body Composition
}

\author{
Sochung Chung* \\ Department of Pediatrics, Konkuk University Medical Center, Konkuk University School of Medicine, Seoul, Korea
}

Childhood obesity is a major public health concern throughout the world. Nutrition, energy balance and hormones interplay in growth and pubertal development regulation. Frequently overweight and obese children are taller for their age and sex and tend to mature earlier than lean children. The increased leptin and sex hormone levels seen in obese children with excessive adiposity may be implicated in accelerated pubertal growth and accelerated epiphyseal growth plate maturation. Efforts to detect the impact of obesity in children are needed to prevent metabolic and cardiovascular disease in later life. This review aims to cover the process of growth in obese children and implications of body composition on growth and pubertal development and introduce the use of body composition charts in clinical practice.

Key words: Growth, Puberty, Obesity, Body composition

\author{
Received July 15, 2017 \\ Reviewed August 20, 2017 \\ Accepted September 8, 2017 \\ *Corresponding author \\ Sochung Chung \\ (iD) \\ https://orcid.org/0000-0002-7655-2691 \\ Department of Pediatrics, Konkuk \\ University Medical Center, Konkuk \\ University School of Medicine, \\ 120-1 Neungdong-ro, Gwangjin-gu, \\ Seoul 05030, Korea \\ Tel: +82-2-2030-7553 \\ Fax: +82-2-2030-7748 \\ E-mail: scchung@kuh.ac.kr
}

\section{INTRODUCTION}

Obesity and related complications are major public health concerns and effective prevention strategies are required. The rising economic burden due to the increase in obesity-related disease treatment costs has emerged as a social challenge for the next generation.

In the human body, essential fats are required for sustaining life and metabolism. However, it is well known that excessive/ectopic fat accumulation is harmful and could be a disease risk even in children. ${ }^{1,2}$ Accurate adiposity evaluation has become the essential component of obesity assessment. ${ }^{3}$

Growth monitoring and nutritional status assessment is the priority in clinical practice for children and pubertal stage assessment is also important in adolescents. The majority of overweight youth become overweight adults. ${ }^{4}$ Body mass index (BMI) is the widely used screening tool in obesity assessment. However, BMI cannot differentiate between fat mass and fat-free mass (FFM) and this limitation might have greater clinical implications in children and aged than in adults. Endocrine etiologies for obesity are rare and usually accompanied by attenuated growth patterns. ${ }^{5}$ Individual height and its percentile or $\mathrm{z}$-score should be accompanied by measures other than BMI and its z-score in childhood obesity evaluation. Asians including Koreans, tend to develop diabetes with a lesser degree of obesity at younger ages and urgent action for lifestyle changes has been called for. ${ }^{6}$

Being underweight or under nourished are risk factors for increased mortality, especially in elderly patients with accompanying 
disease such as coronary heart disease ${ }^{7}$, and in terms of FFM loss in chronic obstructive pulmonary disease ${ }^{8}$, and cancer. ${ }^{9}$

Multiple factors affect the timing and tempo of pubertal development, including environmental conditions. Adequate nutrition is a key permissive factor for the normal timing and tempo of pubertal development. Insulin resistance during puberty may be exaggerated in the condition of obesity. Obesity during childhood may lead to early signs of puberty in girls and pubertal delay in boys; adiposity in early childhood also appears to be linked to advanced puberty in girls and age at menarche is negatively associated with BMI. ${ }^{10}$

Early interventions directed to appropriate maternal nutrition before and during pregnancy, promotion of breast feeding, prevention of rapid weight gain during infancy, and promoting a healthy lifestyle have been increased. ${ }^{11}$

This is a brief review of growth in obese children and adolescents and the impact of obesity on growth and pubertal development in terms of body composition, FFM and fat mass, and scaling these by height.

\section{Growth in children}

Proper growth is the most important factor in health assessment of children and adolescents. Growth can be presented as an increase in height and an increase in body weight. Postnatal linear growth is controlled by genetic, endocrine and nutrition factors. Annual height velocity is approximately $25 \mathrm{~cm}$ in the first year of life, and then decreases over time until a plateau-like phase before the onset of puberty. There are sex-specific differences in height velocity in childhood that is a hallmark of puberty. Pubertal height increase in boys exceeds that of girls and remarkable gender differences exist in annual height velocity during puberty. Girls attain a peak height velocity at an average age of 11-12 years, in boys, it is 13-14 years of age. Growth hormone (GH) through insulin-like growth factor (IGF)-1 plays a major role in postnatal growth, together with thyroid hormones and sex steroids that are active growth stimulators during puberty. ${ }^{12}$ Although adequate nutrition is essential for normal child growth and obese children are usually taller than normal weight peers, they do not tend to attain taller height as adults. ${ }^{13,14}$

Endocrine etiologies for obesity are rare and usually are accompanied by attenuated growth patterns. Short stature associated obe- sity in children may suggest the possibility of endocrine disorders such as hypothyroidism, GH deficiency, Cushing syndrome, pseudohypoparathyroidism, or a genetic syndrome such as Prader-Willi syndrome. ${ }^{5}$

For pubertal development and menstrual function in girls, it is essential to achieve a certain minimum weight or percentage of body fat (PBF): the "critical weight hypothesis." ${ }^{\text {"1,16 }} \mathrm{A}$ secular trend for earlier age at menarche associated with an increase in the prevalence of overweight and obesity has been reported. ${ }^{17}$ An accelerated growth rate in overweight children accompanied by early appearance of pubertal signs may raise the concern of hormonal abnormalities such as precocious puberty.

Obesity screening using BMI percentile is recommended in all children once a year. ${ }^{18} \mathrm{BMI}$ has a curvilinear shape with respect to age and inverted BMI $\left(\mathrm{cm}^{2} / \mathrm{kg}\right)$ has been referred to as a better proxy for body fat in adults. ${ }^{19}$ More attention is required with respect to application of BMI in obesity work-ups in children compare to adults. The calculation of BMI includes height, and if he or she is tall, even if the weight is too high, he or she might be classified as overweight instead of obese, in other words, the risk for obesity complications might be overlooked. In children and adolescents, BMI levels are strongly associated with fat free mass index (FFMI) as FFM makes up about $75 \%$ (girls) to $80 \%$ (boys) of the weight and there is a strong association between FFM and height. ${ }^{20}$ Among children with a BMI-for-age $\geq 85$ th percentile, BMI levels were strongly associated with fat mass index (FMI) ${ }^{20}$

Careful assessment of pubertal status and bone age determination are important for growth assessment in children and adolescents. For better sensitivity in the initial assessment and sequential follow-up of nutritional status, body composition evaluation could be considered in routine clinical practice. ${ }^{3}$

\section{Adiposity rebound in early childhood}

Early childhood has emerged as a critical period for assessing the beginnings of obesity and instituting preventive measures. ${ }^{21}$ It is well-known that early adiposity rebound is a risk factor for adult obesity. ${ }^{22}$ The importance of early-life obesity prevention is increasing and obesity interventions may have the greatest preventive effect if begun early in life. ${ }^{23}$

The "first 1,000 days" - conception through age 24 months- 
are critical for the development and prevention of childhood obesity. Modifiable risk factors for childhood obesity occurring in the first 1,000 days and feeding for healthy infancy weight gain should be addressed. ${ }^{24}$ As most recent studies have reported a positive association between higher infancy weight or weight gain and later childhood overweight ${ }^{24}$, preconception, pregnancy, and early life have emerged as critical periods for obesity prevention.

Beyond milk nutrient composition, there appears to be a linear relationship between total energy intake and weight gain during infancy, at least among formula-fed infants. ${ }^{25}$

A systems-level approach to obesity prevention in early life, including during pregnancy, has been suggested due to the consistent association between rapid growth and weight gain during infancy and higher risks for obesity in later childhood and adult life. ${ }^{26}$ The World Health Organization Commission on Ending Childhood Obesity has called for low- and high income countries to develop multisector approaches to reducing childhood obesity across the life course including during pregnancy (e.g., higher maternal prepregnancy BMI, prenatal tobacco exposure, and excess gestational weight gain), infancy (e.g., high infant birth weight, accelerated infant weight-for-length gain), gestational diabetes, child care attendance, low strength of the maternal infant relationship, curtailed infant sleep, inappropriate bottle use, introduction of solid food intake before age 4 months, and infant antibiotic exposure. ${ }^{27} \mathrm{The} \mathrm{Na-}$ tional Academy of Medicine, formerly called the Institute of Medicine and National Institutes of Health have established obesity prevention intervention development as a priority that must be conducted at systems and policy levels; thus, the challenge is to create population-level obesity prevention interventions that are cost-effective and sustainable. ${ }^{21,27}$

In Korea, health screening program for infant and early childhood undertaken by The National Health Insurance Service might be a powerful tool for early detection of the timing of adiposity rebound and starting early intervention. For a child with a rapid crossing of BMI percentiles, it is necessary to provide parent education and a close monitoring schedule.

\section{Growth in obese children}

Excess adiposity during childhood can affect the process of growth and puberty. Childhood obesity is related to an acceleration in linear growth during prepuberty. Early childhood rapid weight gain is often accompanied by an increase in height velocity and bone age advancement. ${ }^{28,29}$ Advanced skeletal maturity has been shown to precede linear growth acceleration in overweight individuals, as well as subsequent height velocity reduction due to a lesser growth spurt during puberty. ${ }^{13,14,28-30}$

The majority of tall obese children will have a final height reflecting their genetic growth potential, however, in some patients, $a b-$ normal growth caused by pathological processes during childhood needs to be considered. Linear growth is associated with skeletal maturation and the difference in bone age between obese and normal weight children was shown to be significant. ${ }^{14}$ Different patterns of childhood and adolescent height growth have been reported for individuals who became normal weight, overweight or obese as young adults. ${ }^{13}$

According to a longitudinal cohort study, overweight or obese young adults stood taller in childhood, particularly in early childhood, but had relatively less growth in height throughout the teenage years, compared with normal weight young adults..$^{13,30}$

Increased insulin secretion is a normal feature in adolescence and it probably plays a role in activating insulin receptors at the growth plate. Hyperinsulinemia was found to be associated with advanced bone age and was a strong predictor of advanced bone age in obese children. ${ }^{31}$ The hyperinsulinemia seen in obesity is a contributor to GH suppression in obesity. ${ }^{32}$ Obese children have reduced GH secretion with normal IGF-1 levels. ${ }^{33}$ In some clinical conditions such as GH deficiency secondary to craniopharyngioma surgery that are accompanied by the presence of low GH serum levels, in normal growth or even accelerated growth associated with obesity, a "circulating factor" that stimulates growth independent of GH has been observed but remains unidentified. ${ }^{34}$

Puberty is the process by which children develop secondary sexual characteristics and reproductive capacity. Nutrition plays a key role in the timing and tempo of pubertal development. Obesity and increased adiposity may alter hormone secretion and sensitivity, including leptin and insulin.

Insulin resistance and compensatory hyperinsulinemia in adolescents may represent common contributors to pubertal changes, thus interfere at different levels in the process of pubertal development in obese children. ${ }^{35,36}$ Early hyperleptinemia related to over- 
nutrition was associated with early pubertal development. ${ }^{37}$

In prepubertal obese children, adrenal androgens such as dehydroepiandrosterone and androstenedione were increased, as well as free leptin and IGF-1. ${ }^{38}$ High levels of insulin, leptin, and androgens are observed in obese children. Leptin can act as a skeletal growth factor with a direct effect. Increased leptin and androgens may be implicated in earlier onset of puberty and accelerated pubertal growth. ${ }^{39}$ Potential links between low GH and elevated leptin levels associated with increased body fat accumulation in children has been reported. ${ }^{40,41} \mathrm{GH}$ pulsatile secretion was greater in girls with later age at menarche. ${ }^{40}$

High leptin levels and leptin-to-adiponectin ratio may be sexspecific predictors of obesity gain in non-obese and prepubertal children and routine body composition measurement was suggested to assess fat mass growth and distribution during childhood and adolescence. $^{42}$

Obese children are frequently tall for their age, with associated accelerated linear growth. ${ }^{39}$ Accelerated epiphyseal growth plate maturation possibly due to early estrogenization and the action of insulin on the IGF-1 receptor and the degree of body fatness may trigger the neuroendocrine events that lead to the onset of puberty; these may explain the findings that obese girls tend to mature earlier than lean girls. ${ }^{39}$

Rapid weight gain during infancy was a risk factor for both increased childhood adiposity and early menarche in girls ${ }^{43}$, and BMI standard deviation score reduction in overweight children was associated with later onset of puberty in girls, suggesting earlier puberty in obese girls. ${ }^{44}$ Children maturing faster are not only taller for their age but also fatter, and this means that the FMI remains correlated with height. ${ }^{45}$ Bone age advancement after adjusting for age and sex was associated with body fat mass. ${ }^{46}$

\section{Body composition analysis to overcome the limitations of BMI}

The interest in body composition in children is increasing within the context of obesity and it is focused on PBF. Most of the weight gain during growth in children comprises FFM (used here as a synonym for lean mass) rather than fat mass ${ }^{20,47}$ and both increased fat mass and reduced FFM may represent pathways to an increased risk for adult disease. ${ }^{47}$
Body composition is not routinely measured in patients, although body composition evaluation was suggested as a useful tool for clinical practice. ${ }^{3}$ The use of FMI and FFMI improves on the use of PBF and BMI by allowing for the independent assessment of fat mass and FFM. ${ }^{48}$ Growth charts for weight and height have provided the basis for assessment of children's nutritional status. Growth chart data is expressed in age- and sex-specific standard deviation score or percentiles. The majority of children do not cross up or down through the centiles, but tend to track along a given centile, indicating that growth is self-regulating and targetseeking ${ }^{49}$, and abrupt centile crossing is an indication of a clinical growth abnormality.

Growth charts for BMI and age- and sex-specific BMI percentile values have been used in obesity assessment. ${ }^{50-52}$ Age- and sex-specific BMI percentile values are easy to calculate and are correlated with the PBF, especially for high BMI values. However, BMI does not provide information on the proportions of multi components of weight, such as lean mass, fat mass, and bone mass. BMI is correlated with each of these but, it cannot differentiate between them. BMI cutoff values to diagnose obesity have high specificity, but low sensitivity to identify adiposity. ${ }^{53}$ Although a high BMI-for-age is a good indicator of excess fat mass, BMI levels among children should be interpreted with caution. BMI differences among thinner children can be largely due to $\mathrm{FFM}^{20}$, and it is more important in underweight children. PBF also has limitations as an index of adiposity and high PBF values might reflect high fat mass or low FFM $^{54}$

BMI can be divided into two components: the FFMI (FFM/ height ${ }^{2}$ ) and the FMI (fat mass/height ${ }^{2}$ ), each expressed in the same $\mathrm{kg} / \mathrm{m}^{2}$ units as BMI. ${ }^{20,47,55}$ FMI was a better screening tool for predicting the presence of metabolic syndrome than $\mathrm{BMI}$ and $\mathrm{PBF}$ in men and women. ${ }^{56}$

It should be emphasized that body composition data from different techniques cannot be used interchangeably, and existing reference data can only be used if data are collected using the same method. ${ }^{57}$ Interpopulation variability in body composition may derive in part from genetic factors, suggesting a universal human body composition reference may not be viable. ${ }^{57}$

In the Korean pediatric population, characterization of diabetes type and detection of atypical diabetes cases and early adjustment 


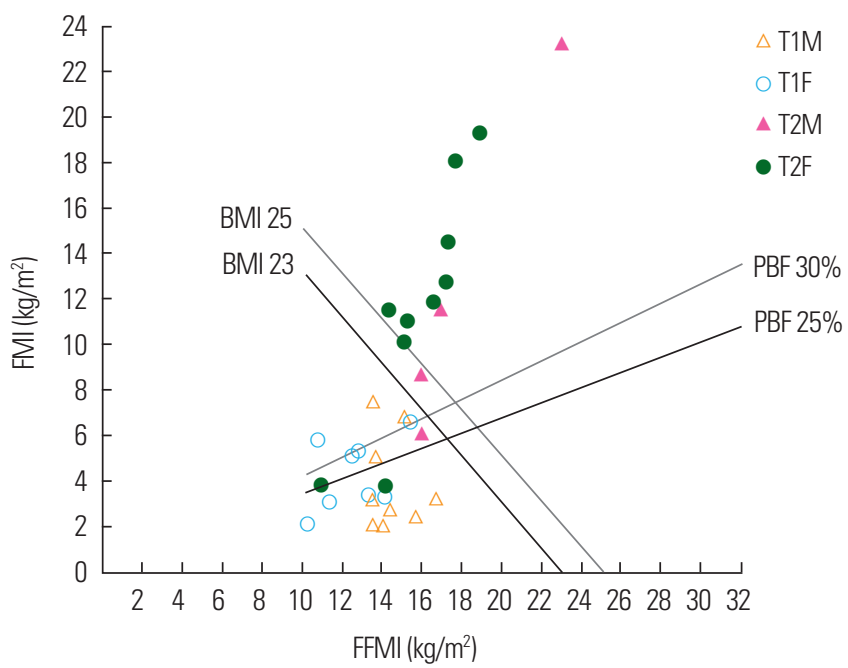

Figure 1. Plotting FFMl and FMl in adolescents with diabetes on a body composition chart. The $\mathrm{X}$-axis represents FFMI, and the $\mathrm{Y}$-axis depicts individual FMI. The lines for BMI and PBF were added to same plane. FMI, fat mass index; BMI, body mass index; PBF, percentage of body fat; FFMl, fat free mass index; T1M, type 1 diabetic boy; T1F, type 1 diabetic girl; T2M, type 2 diabetic boy; T2F, type 2 diabetic girl. Reprinted from Park et al. J Korean Med Sci 2012;27:1385-90.58

of diabetes management strategy using a body composition chart (BC chart) was reported (Fig. 1) ${ }^{58}$ Remission in cases of type 2 diabetes in teenage girls with intensive lifestyle modification that included BC chart monitoring as an aid for motivation has been reported (Fig. 2). ${ }^{59}$ The changes in FFMI and FMI are easily visualized on a BC chart and this is helpful for increasing intervention compliance. Growth charts for children's body composition have been produced and reference values for Korean children have also been presented. ${ }^{60}$ Data from body composition growth charts will improve understanding of the effects of low birth weight, wasting, and stunting as well as obesity in children and later life.

\section{CONCLUSION}

A worldwide epidemic of obesity is an ongoing global health concern and the diagnosis, treatment and monitoring of obesity in the pediatric age group is a priority in global health. Obese children are usually taller for their age but also fatter and mature faster, but they do not tend to attain taller height as adults since excess adiposity during early childhood has an influence on the process of growth and puberty. To discern the impact of excessive fatness in the trajectory of linear growth in obese children early, body composition analysis should be included along with growth and puber-

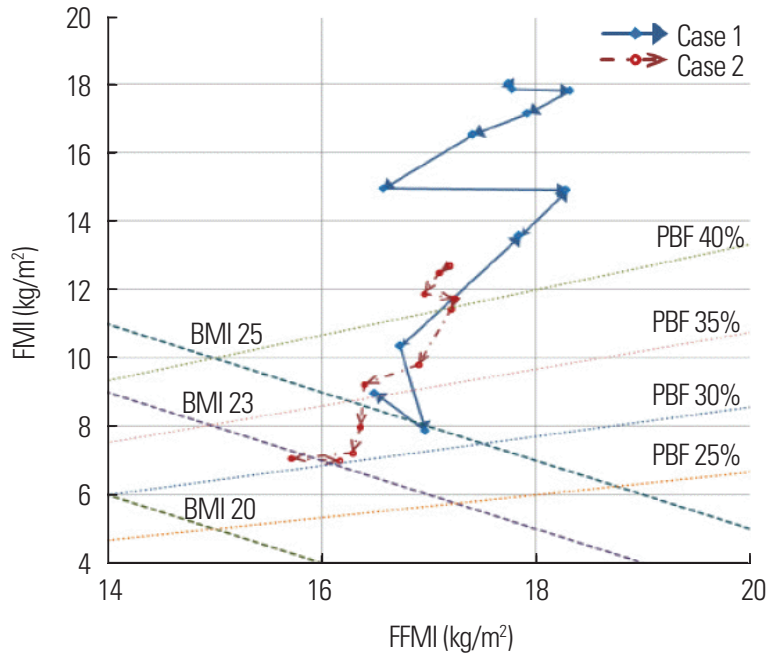

Figure 2. Plot of changes in FFMl and FMl in two adolescent girls with T2DM who achieved remission. FMl, fat mass index; BMl, body mass index; PBF, percentage of body fat; FFMI, fat free mass index; T2DM, type 2 diabetes. Reprinted from Lee et al. J Obes Metab Syndr 2017;26:71-5. ${ }^{59}$

tal status assessment.

A BC chart based on FFMI and FMI along with BMI percentiles for age, sex, and PBF should be included in growth charts along with height, weight, weight for height and BMI. This should be considered an essential part in clinical practice for the pediatric population. Body composition growth charts could be a solution to the need for an easy and accurate tool that can be used in assessment and follow-up to monitor individuals with skewed subclinical metabolic conditions and early cardiovascular risk origins.

\section{CONFLICTS OF INTEREST}

The author declares no conflict of interest.

\section{REFERENCES}

1. Cali AM, Caprio S. Ectopic fat deposition and the metabolic syndrome in obese children and adolescents. Horm Res 2009; 71 Suppl 1:2-7.

2. Bennett B, Larson-Meyer DE, Ravussin E, Volaufova J, Soros A, Cefalu WT, et al. Impaired insulin sensitivity and elevated ectopic fat in healthy obese vs. nonobese prepubertal children. Obesity (Silver Spring) 2012;20:371-5.

3. Thibault R, Pichard C. The evaluation of body composition: 
a useful tool for clinical practice. Ann Nutr Metab 2012;60:616.

4. Whitaker RC, Wright JA, Pepe MS, Seidel KD, Dietz WH. Predicting obesity in young adulthood from childhood and parental obesity. N Engl J Med 1997;337:869-73.

5. Styne DM, Arslanian SA, Connor EL, Farooqi IS, Murad $\mathrm{MH}$, Silverstein JH, et al. Pediatric obesity-assessment, treatment, and prevention: an Endocrine Society Clinical Practice Guideline. J Clin Endocrinol Metab 2017;102:709-57.

6. Yoon KH, Lee JH, Kim JW, Cho JH, Choi YH, Ko SH, et al. Epidemic obesity and type 2 diabetes in Asia. Lancet 2006; 368:1681-8.

7. Gruberg L, Weissman NJ, Waksman R, Fuchs S, Deible R, Pinnow EE, et al. The impact of obesity on the short-term and long-term outcomes after percutaneous coronary intervention: the obesity paradox? J Am Coll Cardiol 2002;39:57884.

8. Vestbo J, Prescott E, Almdal T, Dahl M, Nordestgaard BG, Andersen T, et al. Body mass, fat-free body mass, and prognosis in patients with chronic obstructive pulmonary disease from a random population sample: findings from the Copenhagen City Heart Study. Am J Respir Crit Care Med 2006; 173:79-83.

9. Janiszewski PM, Oeffinger KC, Church TS, Dunn AL, Eshelman DA, Victor RG, et al. Abdominal obesity, liver fat, and muscle composition in survivors of childhood acute lymphoblastic leukemia. J Clin Endocrinol Metab 2007;92:3816-21.

10. Freedman DS, Khan LK, Serdula MK, Dietz WH, Srinivasan SR, Berenson GS. Relation of age at menarche to race, time period, and anthropometric dimensions: the Bogalusa Heart Study. Pediatrics 2002;110:e43.

11. Hernández MI, Mericq V. Metabolic syndrome in children bornsmall-for-gestational age. Arq Bras Endocrinol Metabol 2011;55:583-9.

12. Patel L, Clayton PE. Normal and disordered growth. In: Brook C, Clayton P, Brown R, editors. Clinical pediatric endocrinology. 5th ed. Oxford: Blackwell Publishing; 2008. p. 90112.

13. Stovitz SD, Demerath EW, Hannan PJ, Lytle LA, Himes JH. Growing into obesity: patterns of height growth in those who become normal weight, overweight, or obese as young adults. Am J Hum Biol 2011;23:635-41.

14. He Q, Karlberg J. BMI in childhood and its association with height gain, timing of puberty, and final height. Pediatr Res 2001;49:244-51.

15. Kaplowitz PB. Link between body fat and the timing of puberty. Pediatrics 2008;121 Suppl 3:S208-17.

16. Frisch RE, Revelle R. Height and weight at menarche and a hypothesis of menarche. Arch Dis Child 1971;46:695-701.

17. Euling SY, Herman-Giddens ME, Lee PA, Selevan SG, Juul A, Sørensen TI, et al. Examination of US puberty-timing data from 1940 to 1994 for secular trends: panel findings. Pediatrics 2008;121 Suppl 3:S172-91.

18. US Preventive Services Task Force, Barton M. Screening for obesity in children and adolescents: US Preventive Services Task Force recommendation statement. Pediatrics 2010;125: 361-7.

19. Nevill AM, Stavropoulos-Kalinoglou A, Metsios GS, Koutedakis Y, Holder RL, Kitas GD, et al. Inverted BMI rather than BMI is a better proxy for percentage of body fat. Ann Hum Biol 2011;38:681-4.

20. Freedman DS, Wang J, Maynard LM, Thornton JC, Mei Z, Pierson RN, et al. Relation of BMI to fat and fat-free mass among children and adolescents. Int J Obes (Lond) 2005;29: $1-8$.

21. Institute of Medicine. Early childhood obesity prevention policies. Washington (DC): The National Academies Press; 2011.

22. Whitaker RC, Pepe MS, Wright JA, Seidel KD, Dietz WH. Early adiposity rebound and the risk of adult obesity. Pediatrics 1998;101:E5.

23. Blake-Lamb TL, Locks LM, Perkins ME, Woo Baidal JA, Cheng ER, Taveras EM. Interventions for childhood obesity in the first 1,000 days a systematic review. Am J Prev Med 2016;50:780-9.

24. Woo Baidal JA, Locks LM, Cheng ER, Blake-Lamb TL, Perkins ME, Taveras EM. Risk factors for childhood obesity in the first 1,000 days: a systematic review. Am J Prev Med 2016; 50:761-79.

25. Ong KK, Emmett PM, Noble S, Ness A, Dunger DB; ALSPAC Study Team. Dietary energy intake at the age of 4 
months predicts postnatal weight gain and childhood body mass index. Pediatrics 2006;117:e503-8.

26. Nader PR, Huang TT, Gahagan S, Kumanyika S, Hammond RA, Christoffel KK. Next steps in obesity prevention: altering early life systems to support healthy parents, infants, and toddlers. Child Obes 2012;8:195-204.

27. World Health Organization. Interim report of the commission on ending childhood obesity [Internet]. Geneva: World Health Organization; 2015 [cited 2017 Oct 30]. Available from: http://www.who.int/end-childhood-obesity/commission-ending-childhood-obesity-interim-report.pdf?ua=1

28. Akaboshi I, Haraguchi Y, Mizumoto Y, Kitano A, Kan H. Taller stature after postnatal rapid weight gain in early infancy predicts overweight status at age 3. Acta Paediatr 2008;97:14604.

29. Sopher AB, Jean AM, Zwany SK, Winston DM, Pomeranz $\mathrm{CB}$, Bell JJ, et al. Bone age advancement in prepubertal children with obesity and premature adrenarche: possible potentiating factors. Obesity (Silver Spring) 2011;19:1259-64.

30. Freedman DS, Khan LK, Mei Z, Dietz WH, Srinivasan SR, Berenson GS. Relation of childhood height to obesity among adults: the Bogalusa Heart Study. Pediatrics 2002;109:E23.

31. Pinhas-Hamiel O, Benary D, Mazor-Aronovich K, Ben-Ami M, Levy-Shraga Y, Boyko V, et al. Advanced bone age and hyperinsulinemia in overweight and obese children. Endocr Pract 2014;20:62-7.

32. Luque RM, Kineman RD. Impact of obesity on the growth hormone axis: evidence for a direct inhibitory effect of hyperinsulinemia on pituitary function. Endocrinology 2006;147: 2754-63.

33. Scacchi M, Pincelli AI, Cavagnini F. Growth hormone in obesity. Int J Obes Relat Metab Disord 1999;23:260-71.

34. Geffner ME. The growth without growth hormone syndrome. Endocrinol Metab Clin North Am 1996;25:649-63.

35. Burt Solorzano CM, McCartney CR. Obesity and the pubertal transition in girls and boys. Reproduction 2010;140:399410.

36. Pilia S, Casini MR, Foschini ML, Minerba L, Musiu MC, Marras V, et al. The effect of puberty on insulin resistance in obese children. J Endocrinol Invest 2009;32:401-5.
37. Elias CF, Purohit D. Leptin signaling and circuits in puberty and fertility. Cell Mol Life Sci 2013;70:841-62.

38. l'Allemand D, Schmidt S, Rousson V, Brabant G, Gasser T, Grüters A. Associations between body mass, leptin, IGF-1 and circulating adrenal androgens in children with obesity and premature adrenarche. Eur J Endocrinol 2002;146:537-43.

39. Shalitin S, Kiess W. Putative effects of obesity on linear growth and puberty. Horm Res Paediatr 2017;88:101-10.

40. Kasa-Vubu JZ, Ye W, Borer KT, Rosenthal A, Meckmongkol T. Twenty-four hour growth hormone and leptin secretion in active postpubertal adolescent girls: impact of fitness, fatness, and age at menarche. J Clin Endocrinol Metab 2006;91:393540.

41. Shalitin S, Phillip M. Role of obesity and leptin in the pubertal process and pubertal growth: a review. Int J Obes Relat Metab Disord 2003;27:869-74.

42. Zhang M, Cheng H, Zhao X, Hou D, Yan Y, Cianflone K, et al. Leptin and leptin-to-adiponectin ratio predict adiposity gain in nonobese children over a six-year period. Child Obes 2017;13:213-21.

43. Ong KK, Emmett P, Northstone K, Golding J, Rogers I, Ness $\mathrm{AR}$, et al. Infancy weight gain predicts childhood body fat and age at menarche in girls. J Clin Endocrinol Metab 2009;94: 1527-32.

44. Reinehr T, Bosse C, Lass N, Rothermel J, Knop C, Roth CL. Effect of weight loss on puberty onset in overweight children. J Pediatr 2017;184:143-50.e1.

45. Cole TJ. Weight-stature indices to measure underweight, overweight, and obesity. In: Himes JH, editor. Anthropometric assessment of nutritional status. New York: Wiley-Liss; 1991. p. 83-111.

46. Kwon JH, Lee HA, Kim YJ, Lee H, Park EA, Cho SJ, et al. Effects of adrenal androgen levels on bone age advancement in prepubertal children: using the Ewha Birth and Growth Cohort Study. J Korean Med Sci 2017;32:968-73.

47. Wells JC. Body composition in childhood: effects of normal growth and disease. Proc Nutr Soc 2003;62:521-8.

48. Weber DR, Moore RH, Leonard MB, Zemel BS. Fat and lean BMI reference curves in children and adolescents and their utility in identifying excess adiposity compared with BMI and 
percentage body fat. Am J Clin Nutr 2013;98:49-56.

49. Tanner JM. The regulation of human growth. Child Dev 1963;34:817-47.

50. Cole TJ, Bellizzi MC, Flegal KM, Dietz WH. Establishing a standard definition for child overweight and obesity worldwide: international survey. BMJ 2000;320:1240-3.

51. Cole TJ, Flegal KM, Nicholls D, Jackson AA. Body mass index cut offs to define thinness in children and adolescents: international survey. BMJ 2007;335:194.

52. Moon JS, Lee SY, Nam CM, Choi JM, Choe BK, Seo JW, et al. 2007 Korean National Growth Charts: review of developmental process and an outlook. Korean J Pediatr 2008;51:125.

53. Okorodudu DO, Jumean MF, Montori VM, Romero-Corral A, Somers VK, Erwin PJ, et al. Diagnostic performance of body mass index to identify obesity as defined by body adiposity: a systematic review and meta-analysis. Int J Obes (Lond) 2010;34:791-9.

54. Wells JC, Mok Q Johnson AW. Nutritional status in children. Lancet 2001;357:1293.
55. VanItallie TB, Yang MU, Heymsfield SB, Funk RC, Boileau RA. Height-normalized indices of the body's fat-free mass and fat mass: potentially useful indicators of nutritional status. Am J Clin Nutr 1990;52:953-9.

56. Liu P, Ma F, Lou H, Liu Y. The utility of fat mass index vs. body mass index and percentage of body fat in the screening of metabolic syndrome. BMC Public Health 2013;13:629.

57. Wells JC. Toward body composition reference data for infants, children, and adolescents. Adv Nutr 2014;5:320S-329S.

58. Park HW, Kim YH, Cho M, Kwak BO, Kim KS, Chung S. Adolescent build plotting on body composition chart and the type of diabetes mellitus. J Korean Med Sci 2012;27:1385-90.

59. Lee SH, Cho MH, Kim YH, Chung S. Two cases of successful type 2 diabetes control with lifestyle modification in children and adolescents. J Obes Metab Syndr 2017;26:71-5.

60. Park HW, Yoo HY, Kim CH, Kim H, Kwak BO, Kim KS, et al. Reference values of body composition indices: the Korean National Health and Nutrition Examination Surveys. Yonsei Med J 2015;56:95-102. 